\title{
TERMO DE AJUSTAMENTO DE GESTÃO - TRANSPARÊNCIA COMO PRINCÍPIO NORTEADOR QUANDO DA PARTICIPAÇÃO DE ENTE PÚBLICO
}

\author{
César Ferreira Mariano da Paz \\ Frederico Rodrigues Assumpção ${ }^{* *}$
}

\section{RESUMO:}

O presente artigo tem por objetivo geral analisar o Termo de Ajustamento de Gestão enfocando a transparência como princípio norteador quando da participação de ente público. Os objetivos específicos buscam apresentar o Termo de Ajustamento de Conduta destacando a sua natureza jurídica, classificação e modalidade; e, investigar a relevância do Termo de Ajustamento de Gestão visando à necessidade da publicidade. A metodologia deste estudo caracteriza-se pela pesquisa de revisão bibliográfica. Constatou-se que, embora haja previsão de publicação do TAG no Diário Oficial, na prática não há nenhum mecanismo que permita o controle e a fiscalização pelos cidadãos, o que fulmina o princípio democrático.

PALAVRAS-CHAVE: Termo. Ajustamento. Gestão. Sigilo. Publicidade.

\section{MANAGEMENT ADJUSTMENT TERM - TRANSPARENCY AS A GUIDING PRINCIPLE WHEN PARTICIPATION BY THE PUBLIC}

\begin{abstract}
:
This article aims to analyze the Management Adjustment Term focusing on transparency as a guiding principle when involving a public entity. The specific objectives seek to present the Conduct Adjustment Term highlighting its legal nature, classification and modality; and investigate the relevance of the Management Adjustment Term aiming at the need for advertising. The methodology used for this study is characterized by the literature review research. It was found that although there is provision for publication of the TAG in the Official Gazette, in practice there is no mechanism that allows the control and enforcement by citizens, which undermines the democratic principle.
\end{abstract}

KEYWORDS: Term. Adjustment. Management. Secrecy. Publicity.

\section{INTRODUÇÃO}

\footnotetext{
* Policial Militar do Estado de Minas Gerais. Tutor da Secretária Nacional de Segurança Pública - SENASP. Bacharel em Direito pela Faculdade de Direito de Conselheiro Lafaiete - FDCL. Pós-graduado em Direito Penal e Processual Penal pela Faculdade de Direito Damásio de Jesus - FDDJ, Pós-Graduado em Direito Tributário pela Universidade Cândido Mendes - UCAM. Mestrando em Direito do Programa de Pós-Graduação Stricto Sensu em Proteção dos Direitos Fundamentais da Universidade de Itaúna/MG, Brasil. Eletrônico: cesarferreiradapaz@yahoo.com.br

** Tabelião de Notas. Mestrando em Direito do Programa de Pós-Graduação Stricto Sensu em Proteção dos Direitos Fundamentais da Universidade de Itaúna/MG, Brasil. Eletrônico: fredsilva14@yahoo.com.br
}

\section{Revista Cidadania e Acesso a Justiça | e-ISSN: 2526-026X | Belém | v. 5 | n. 2 | p. 78 - 94 |} Jul/Dez. 2019. 
O Termo de Ajustamento de Conduta - TAC -, também conhecido como compromisso de ajustamento de conduta, foi primeiramente previsto no artigo 211 do Estatuto da Criança e do Adolescente (Lei no . 8.069, 1990, art. 211). Posteriormente, o TAC também passou a constar na Lei de Ação Civil Pública (Lei n ${ }^{\circ} 7.347,1985$, artigo $5^{\circ}$, parágrafo $6^{\circ}$ ).

Conforme Ferreira (2018) em relação ao instituto jurídico comenta que:

\begin{abstract}
Mediante revisão doutrinária, jurisprudencial e normativa, o instituto jurídico configurou-se como um negócio jurídico bilateral, consensual e formal, que pode e deve ser impulsionado por estratégias de conciliação e mediação e que, após celebrado, constitui-se em garantia mínima em prol dos direitos coletivos protegidos, constituindo-se título executivo extrajudicial ou judicial, caso celebrado em juízo. (FERREIRA, 2018, p.03).
\end{abstract}

O conceito acima mencionado introduz o tema e facilita o entendimento sobre o Termo de Ajustamento de Gestão - TAG -, "variável paralela ao Termo de Ajustamento de Conduta" (FERREIRA, 2018, p. 134) a fim de que se possa analisar se a participação do ente público na celebração do TAG está sujeito a algum grau de sigilo.

O Termo de Ajustamento de Gestão foi introduzido, no ano de dois mil e onze, pela Lei Complementar $n^{\circ} 102 / 2008$, que dispõe sobre a organização do Tribunal de Contas do Estado de Minas Gerais, que estabelece, em seu Art. 93:

Art. 93-A. Fica instituído, no âmbito do Tribunal de Contas, Termo de Ajustamento de Gestão para regularizar atos e procedimentos dos Poderes, órgãos ou entidades por ele controlados.

$\S 1^{\circ} \mathrm{O}$ Termo de Ajustamento a que se refere o caput poderá ser proposto pelo Tribunal de Contas ou pelos Poderes, órgãos e entidades por ele controlados, desde que não limite a competência discricionária do gestor.

$\S 2^{\circ}$ A assinatura de Termo de Ajustamento de Gestão suspenderá a aplicação de penalidades ou sanções, conforme condições e prazos nele previstos.

$\S 3^{\circ}$ É vedada a assinatura de Termo de Ajustamento de Gestão nos casos em que esteja previamente configurado o desvio de recursos públicos e nos casos de processos com decisão definitiva irrecorrível.

$\S 4^{\circ}$ Nos casos em que o Termo de Ajustamento de Gestão impuser obrigações a particulares, por via direta ou reflexa, estes serão notificados previamente, observado o devido processo legal.

$\S 5^{\circ}$ Os efeitos decorrentes da celebração de Termo de Ajustamento de Gestão não serão retroativos se resultarem no desfazimento de atos administrativos ampliativos de direito, salvo no caso de comprovada má-fé.

$\S 6^{\circ} \mathrm{O}$ não cumprimento das obrigações previstas no Termo de Ajustamento de Gestão pelas autoridades signatárias enseja sua automática rescisão.

$\S 7^{\circ}$ Cumpridas as obrigações previstas no Termo de Ajustamento de Gestão, o processo relativo aos atos e procedimentos objeto do termo será arquivado.

$\S 8^{\circ} \mathrm{O}$ Termo de Ajustamento de Gestão será publicado na íntegra no Diário Oficial Eletrônico do Tribunal de Contas. (Lei Complementar $n^{\mathbf{0}} 102 / 2008$ MINAS GERAIS, 2008)

\title{
Revista Cidadania e Acesso a Justiça | e-ISSN: 2526-026X | Belém | v. 5 | n. 2 | p. 78 - 94 |
} Jul/Dez. 2019. 
Conforme se depreende da leitura da norma, objetiva-se, com o TAG, regularizar atos e procedimentos dos Poderes, órgãos e entidades. Em síntese, os principais aspectos do TAG são os seguintes: a legitimidade para a propositura é do próprio Tribunal de Contas ou dos Poderes, órgãos e entidades; a assinatura do termo poderá suspender a aplicação de penalidades ou sanções; é vedado nos casos de desvio de recursos públicos e também nos processos com decisão irrecorrível; cumpridas as obrigações previstas, o processo será arquivado; será publicado na íntegra no Diário Oficial Eletrônico do Tribunal de Contas. (SANTOS, 2017).

Constata-se, pois, que não há na norma estadual nenhuma previsão de sigilo referente ao TAG. A previsão de publicação do termo no Diário Oficial teria, em princípio, objetivo diverso, ou seja, tornar de conhecimento do público a íntegra do acordo. (CUNHA, 2008)

Ocorre, porém, que, apesar da previsão de publicidade, não há mecanismos que deem efetividade à transparência. Uma pesquisa no sítio do Tribunal de Contas do Estado de Minas Gerais não nos permite verificar a íntegra dos termos de ajustamento de gestão já celebrados.

O objetivo geral do estudo visa analisar o Termo de Ajustamento de Gestão enfocando a transparência como princípio norteador quando da participação de ente público. Os objetivos específicos buscam apresentar o Termo de Ajustamento de Conduta destacando a sua natureza jurídica, classificação e modalidade; e, investigar a relevância do Termo de Ajustamento de Gestão visando à necessidade da publicidade.

Justifica a escolha do tema em razão do aprofundamento sobre os termos de ajustamento de gestão e de conduta no ordenamento jurídico brasileiro, salientando que a conciliação é apontada como um instrumento que pode possibilitar a agilidade nos processos, enfatizando ainda que, o Termo de Ajustamento de Gestão pode propiciar a maior efetivação das normas que regem a justiça propiciando a garantia dos direitos e deveres coletivos dos indivíduos. Sendo assim a justificativa do desenvolvimento do estudo se pauta em saber se as tratativas para um eventual TAG impõem sigilo; se realmente existem meios acessíveis para a consulta dos termos de ajustamento de gestão já celebrados.

A metodologia utilizada para este estudo caracteriza-se pela pesquisa de revisão bibliográfica. Os instrumentos utilizados para a coleta de informações configuram-se como sendo sites, revistas, periódicos, bibliografias de autores que dissertam sobe o tema abordado, propiciando o entendimento do Termo de Ajustamento de Gestão e suas prerrogativas.

\section{Revista Cidadania e Acesso a Justiça | e-ISSN: 2526-026X | Belém | v. 5 | n. 2 | p. 78 - 94 |} Jul/Dez. 2019. 


\title{
2 TERMO DE AJUSTAMENTO DE CONDUTA: SEMÂNTICA E VANTAGENS
}

A expressão "Termo de Ajustamento de Conduta" remete a um conceito jurídico indeterminado. Neste contexto é necessário recorrer à legislação, em especial à Constituição e ainda à jurisprudência e à doutrina para a compreensão adequada da expressão (ZANETI JÚNIOR, 2007).

É possível o entendimento em relação ao primeiro vocábulo da expressão não há indeterminação, ou seja, 'termo' é sinônimo de instrumento formal, escrito. 'Ajustamento' e 'conduta', por outro lado, são vocábulos sujeitos a interpretação. Sendo assim, Ferreira (2018) com o intuito de esclarecer o conceito de ajustamento relata que:

\begin{abstract}
Ajustamento poderá significar um ajuste parcial ou total, em maior ou menor escala, indefinida quantitativamente e qualitativamente portanto, bem como temporalmente ainda indefinida, de uma conduta meramente inadequada ou frontalmente contrária ao ordenamento jurídico, constituindo-se em ilícita, ilegítima ou imoral, entre outras várias possibilidade. (FERREIRA, 2018, p. 113).
\end{abstract}

Conforme a citação apresentada, a expressão “Termo de Ajustamento de Conduta" é um exemplo de conceito jurídico indeterminado. Poder-se-ia dizer que esta compreensão se apresenta por conferir grande margem de interpretação para os operadores do Direito podendo acarretar insegurança jurídica. Embora a afirmação seja válida, não se pode dizer que tal característica seja prejudicial no caso do TAC, pois esta abertura permite que diversas condutas seja objeto de compromisso. Ou seja, a indeterminação da expressão possibilita benefícios, e não o contrário.

Sendo o TAC uma decisão que compete às partes envolvidas, o que se expressa é precisamente a segurança jurídica. Outras virtudes são a rapidez, a economia e a pacificação social. Conforme defendem os autores Cappelletti; Garth (1988, p. 86), “a solução consensual de conflitos é bastante útil para restaurar relacionamentos".

Por isso, por permitir a solução consensual de conflitos e depender sempre da aquiescência das partes envolvidas, a indeterminação da expressão "Termo de Ajustamento de Conduta" na verdade colabora com a segurança jurídica, uma vez que permite aos legitimados buscar diversas alternativas para a solução do problema. (COSTA, 2014)

Tendo em vista o que se defendeu acima, se por um lado há vantagens na indeterminação do conceito, deve-se assentar, por outro lado, que as partes não poderão 
infringir o ordenamento jurídico quando da celebração do TAC. Ou seja, para que o TAC seja exigível, este deverá trazer uma obrigação lícita, consensual, exigível, certa em sua existência e determinada quanto ao seu objeto. (MAZZILLI, 2008, p. 408).

Sendo assim, configura-se em relação ao termo de ajustamento o fato de que apresenta vantagens referentes a indeterminação de seus conceitos, promovendo o entendimento referente a infração do ordenamento jurídico, evidenciando a sua relevância no ordenamento jurídico brasileiro.

Dessa maneira, faz-se relevante a análise da natureza jurídica do TAC, evidenciando o desenvolvimento de conceitos que se encontram no Direito brasileiro.

\section{TERMO DE AJUSTAMENTO DE CONDUTA: NATUREZA JURÍDICA}

Em relação ao Termo de Ajustamento de Conduta, Rodrigues (2011) relata a posição de ajuste ou negócio jurídico consensual bilateral enfatizando que:

\footnotetext{
É um negócio da Administração que também tem natureza de equivalência jurisdicional, por ser um meio alternativo de solução de conflito. Podemos concluir que o ajustamento de conduta é um acordo, um negócio jurídico bilateral, que tem apenas o efeito de acertar a conduta do obrigado às exigências legais. (RODRIGUES, 2011, p. 138).
}

Compreende-se embasando na citação acima, que o ajustamento de conduta se estabelece como um acordo que tem por finalidade o cumprimento das exigências legais que propicia o desenvolvimento dos processos, enfatizando que a sua prática favorece a agilidade dos processos que se encontram em trâmite jurídico.

Por outro lado, Pereira (2006, p. 124) afirma que o TAC "é uma modalidade específica de transação”. Didier Júnior; Zaneti Júnior (2008, p. 329) relatam que "o TAC como uma modalidade de acordo com nítida finalidade conciliatória". Neste sentido, salientas que, o TAC para os autores citados é definido como sendo um acordo que permite a conciliação do obrigado com os juristas, permitindo a solução dos processos jurídicos que precisam ser estabelecidos tendo como princípio o reconhecimento do indivíduo e a sua condição perante a garantia de seus direitos e deveres.

Mazzilli (2008), por sua vez, não entende o TAC como contrato, apresentando dois motivos: primeiramente, porque seu objeto não são direitos patrimoniais de caráter privado; em segundo lugar, porque o órgão público que o toma não é titular do direito transindividual

\section{Revista Cidadania e Acesso a Justiça | e-ISSN: 2526-026X | Belém | v. 5 | n. 2 | p. 78 - 94 | Jul/Dez. 2019.}


nele objetivado, e, como não pode dispor do direito material, não pode fazer concessões quanto ao conteúdo material da lide. Aprofundando a sua explanação referente ao TAC, Mazzilli (2008) relata que:

Nem se diga que o compromisso teria natureza contratual porque o órgão público nele também assumiria uma obrigação, qual seja a de fiscalizar o seu cumprimento. Essa obrigação não tem caráter contratual, e decorre do poder de polícia da Administração, tanto que, posto omitida qualquer cláusula a respeito do instrumento, mesmo assim subsiste por inteiro o poder de fiscalizar. (MAZZILLI, 2008, p. 404).

Para o autor supracitado, o TAC apresenta-se como uma ação que decorre a obrigação do órgão público de fiscalizar o cumprimento do termo, salientando que, por este motivo, não confere um acordo, mas sim, uma ação de caráter que é de compromisso da polícia de administração.

Nota-se que, embora haja divergências pontuais, há um consenso doutrinário quando se diz que o Termo de Ajustamento de Conduta tem natureza jurídica de negócio jurídico consensual e bilateral. É esta também a opinião do autor Ferreira (2018) que esclarece:

\begin{abstract}
A natureza jurídica da essência do TAC é invariavelmente de negócio jurídico consensual e bilateral. Porém, há aspectos adicionais de sua natureza jurídica que não podem ser definitivamente caracterizadas a priori, ou seja, antes de se conhecer seus termos, tendo em vista que num TAC preventivo, verbi gratia, não haverá nenhuma transação nem sequer haverá dano, conduzindo-se a conduta do celebrante para que este não venha a cometer ilícitos. Sob outro ponto de análise, num TAC repressivo em que seja impossível a reparação do dano através da mesma espécie de obrigação de fazer ou não fazer consubstanciada na tutela específica far-se-á necessária a realização de transação para se transformar a solução da questão, nos limites em que isso seja possível, e ajustar novas obrigações que venham a ser possivelmente equivalentes àquela obrigação original descumprida pelo infrator da norma jurídica. (FERREIRA, 2018, p. 119).
\end{abstract}

Assim, segundo o citado autor, a natureza jurídica do TAC dependerá da espécie de consenso. Enquanto no TAC preventivo não haverá transação, tendo em vista que o objetivo é fazer com que o celebrante não venha a cometer ilícitos, por outro lado, no TAC repressivo no qual seja impossível a reparação do dano, poderá haver transação.

Coadunamos com o posicionamento acima exposto, uma vez que, em sendo o TAC uma ideia jurídica indeterminada, sua natureza jurídica variará na medida em que variar também o seu objeto.

Dessa forma, também se pode dizer que a natureza jurídica do compromisso varia conforme o TAC seja formal ou substancial. O TAC formal tem "natureza jurídica de 
compromisso ou negócio jurídico bilateral a ser fiscalizado pelo legitimado público, havendo apenas a estipulação de prazo para o atendimento da tutela específica, por exemplo," (FERREIRA, 2018, p. 118). Ainda de acordo com o autor, o TAC substancial, por sua vez, tem natureza jurídica de transação.

A polêmica acerca de aspectos que envolvem o TAC não diz respeito apenas à sua natureza jurídica. Há divergências também quanto à possibilidade de conciliação na seara da improbidade administrativa. Embora a maioria dos doutrinadores entenda não haver possibilidade de conciliação, Cunha (2008) apresenta-se contrário a esta afirmação. Já Mancuso (2009, p.269) entende ser proibida a possibilidade de transação em matéria de improbidade administrativa.

Embasando-se nos estudos realizados por Martins Júnior (2009, p. 415), sobre o TAC, afirma ser possível a ocorrência de natureza jurídica de "delação premiada". Esta possibilidade se respalda na busca de informações que contribuam para solucionar os processos jurídicos que necessitam se comprovações dos envolvidos, o que em troca das informações conjuga-se o termo de ajustamento, possibilitando até mesmo a redução da pena em razão da colaboração dos envolvidos.

Para tanto, atentando para os estudos realizados por Alves (2008), a sua defesa em relação ao TAC se faz ao afirmar de que se trata de uma circunstância atenuante para eventuais sanções que vem a ser impostas.

Nota-se, que são variadas as opiniões, conceitos e definições acerca da natureza jurídica do Termo de Ajustamento de Conduta. O objeto do trabalho, porém, não nos permite adentrar e tomar posição sobre a natureza jurídica do TAC. Os posicionamentos acima transcritos são contribuições para o entendimento do termo bem como, referências para reflexões e também para demarcar um conceito que permita prosseguir o aprofundamento referente ao tema vislumbrando o entendimento claro das ponderações referentes ao TAC. (COSTA, 2014)

Dessa forma, o conceito que é evidenciado por Ferreira (2018) em relação ao TAC permite o entendimento referente a este termo presente no ordenamento jurídico, sendo possível a leitura de sua afirmação que se apresenta da seguinte maneira:

Negócio jurídico bilateral, consensual e formal, que produza efeitos inter partes e pode ser impulsionado por estratégias de conciliação ou mediação, além de que, depois de celebrado, constitui-se em garantia mínima em prol dos direitos coletivos

\section{Revista Cidadania e Acesso a Justiça | e-ISSN: 2526-026X | Belém | v. 5 | n. 2 | p. 78 - 94 |} Jul/Dez. 2019. 
protegidos, constituindo-se título executivo extrajudicial ou judicial, caso celebrado em juízo. (FERREIRA, 2018, p. 121).

Portanto, em relação à definição e conceituação do Termo de Ajustamento de Conduta em relação a sua natureza jurídica, faz-se relevante o entendimento de que se trata de um negócio que apesenta características que são determinadas de forma bilateral, consensual e formal, sendo de grande valia para o prosseguimento dos processos por permitir acordos que elucidem os casos, propiciando a garantia dos direitos e deveres dos indivíduos de maneira a fazer cumprir o negócio por meio do acompanhamento das autoridades cabíveis para a fiscalização e monitoramento do 'negócio' realizado.

Para tanto, em virtude da explanação frente ao TAC e a sua natureza jurídica, faz-se de suma relevância a análise referentes às classificações e modalidades de composição do TAC, enfatizando o aprofundamento dos conhecimentos frente as especificidades em que ocorrem a aplicação do termo.

\section{TAC: CLASSIFICAÇÕES E MODALIDADE DE COMPOSIÇÃO NA QUAL ESTÁ INSERIDA}

As classificações de TAC apresentam-se como sendo os diferentes tipos que podem ser aplicados no ordenamento jurídico em busca de solucionar os conflitos existentes e fazer cumprir os direitos coletivos e individuais dos indivíduos, quando estes se encontram em foco. (SANTOS, 2017)

Tal classificação não tem o objetivo de trazer ao trabalho, de forma exaustiva, todas as espécies de TAC existentes no ordenamento jurídico pátrio, mas servirá, sobretudo, para o aprofundamento do conhecimento sobre o tema.

Sobre a sua classificação, a conduta a ser efetivada no TAC pode ser de duas formas, como são apresentadas por Ferreira (2018):

O Termo de Ajustamento de Conduta pode ser formal ou material. O TAC em sentido formal ou tradicional implica, por exemplo, em conceder mais prazos. $\mathrm{O}$ TAC em sentido material ou substancial, por sua vez, envolve o "fundo de direito" e implica, necessariamente, em uma transação. O TAC em sentido material deve ser utilizado apenas quando não for possível a utilização do TAC em sentido formal, conforme doutrina de Diogo Ribeiro Ferreira (FERREIRA, 2018, p. 12).

\section{Revista Cidadania e Acesso a Justiça | e-ISSN: 2526-026X | Belém | v. 5 | n. 2 | p. 78 - 94 |} Jul/Dez. 2019. 
De acordo com Rodrigues (2011), a classificação do TAC se apresenta baseada em duas possibilidades, sendo elas, parcial ou total. Em relação à classificação parcial, esta ocorrerá quando não envolver a totalidade de um inquérito civil público promovido pelo Ministério Público; e, por outro lado, será classificada como total, quando abranger todo o objetivo do mesmo inquérito civil. (MAZZILLI, 2018).

O Termo de Ajustamento de Conduta também poderá ser posterior e sucessivo, “ou seja, a realização de um novo TAC para a adequação da conduta às novas circunstâncias de fato ou para complementação do TAC anterior" (FERREIRA, 2018, p. 110). E, ainda de acordo com Ferreira (2018), o TAC pode ter poderá apresentar-se classificado como judicial e extrajudicial.

Importante ressalvar que, seja qual for à classificação adotada, o TAC sempre terá como objetivo transformar uma conduta inadequada juridicamente em uma conduta jurídica adequada. Trindade (2008) comenta que, isso remete à transformação social, à resolutividade jurídica e ao Direito enquanto mecanismo a um só tempo transformador e transformado, impulsionador e impulsionado.

Em relação à modalidade de composição do TAC, esta se apesenta relacionada com a jurisdição, sendo compreendida como sendo a vontade estatal por meio do ato de vontade. (PAIXÃO JÚNIOR, 2002)

Conforme defende Paixão Júnior (2002), a jurisdição deve ser entendida como exteriorização da vontade estatal por meio de ato de vontade. Cappelletii (1994) afirma que, a jurisdição é uma forma de heterocomposição. Há, por outro lado, equivalentes jurisdicionais, ou seja, métodos alternativos de resolução de conflitos, quais sejam: arbitragem, autotutela e autocomposição.

A arbitragem, assim como a jurisdição, é um método heterônomo de resolução de conflitos, pois, conforme prevê a Lei 9.307/1996, a decisão caberá a um terceiro. (RODRIGUES, 2011)

A autocomposição, por sua vez, é o método no qual as próprias partes encontram a solução para o conflito. E a autotela, finalmente, tem como principal exemplo a legítima defesa, modalidade de resolução de conflito na qual a ausência do Estado permite à parte o exercício da força. (THEODORO JÚNIOR, 2013) 
A conciliação e a mediação classificam-se como modalidades de autocomposição. E aqui há alguma semelhança com o instituto do Termo de Ajustamento de Conduta. Conforme doutrina de Diogo Ribeiro Ferreira, "Em sentido amplo pode-se arriscar a dizer que a mediação é uma conciliação qualificada e com critérios específicos, enquanto que o TAC seria uma conciliação em direitos coletivos na forma da lei” (FERREIRA, 2018, p. 18).

Assim sendo, deveria haver maiores incentivos para que os litígios fossem dirimidos sem a necessidade de intervenção do Judiciário. Porém, ocorre o contrário, ou seja, é possível afirmar que, embora largamente prevista na legislação, ainda não se implantou em nosso país uma cultura favorável à conciliação, uma vez que as partes ainda tem o hábito de levar qualquer questão à apreciação do Judiciário. (SANTOS, 2017)

Em relação à legislação vigente referente à política de cultura favorável de conciliação, a Lei n ${ }^{o}$ 13.105/2015, do Código do Processo Civil - CPC brasileiro, em seu Art. $1^{\circ} \S 3^{\circ}$, estabelece que, "a conciliação, a mediação e outros métodos de solução consensual de conflitos deverão ser estimulados por juízes, advogados, defensores públicos e membros do Ministério Público, inclusive no curso do Processo Judicial”.

Rodrigues (2011, p. 281) defende a utilização do Termo de Ajustamento de Conduta como instrumento de conciliação e participação democrática, advogando que o TAC "é um importante instituto para a concreção dos objetivos do Estado Democrático de Direito".

É no sentido de participação democrática, portanto, que se demonstra a necessidade de transparência na utilização do Termo de Ajustamento de Gestão, variável paralela do TAC, conforme já exposto. Antes disso, porém, faz-se relevante o conhecimento das semelhanças existentes entre a conciliação e o TAC, a fim de evidenciar que a utilização de ambos necessita de incentivos, uma vez que, têm como objetivo a efetivação do princípio democrático. (OMMATI, 2017)

Sendo assim, pautando nas reflexões realizadas por Ferreira (2018) em relação as semelhanças entre a conciliação e o TAC, é possível destacar que:

Destacam-se as inúmeras semelhanças entre os institutos da conciliação e do
compromisso de ajustamento de conduta, quais sejam: são formas de composição
autônoma; relatórios nacionais do Ministério da Justiça apontam sua efetividade;
podem ser rápidos e trazer segurança jurídica; são pontos de equilíbrio entre dois
pontos extremos (reconhecimento da procedência do pedido e renúncia ao objeto da
ação); são temas contemporâneos; não devem ser buscados por mero medo de
ressentimento do juiz; podem restaurar relacionamentos prolongados, porém não
devem ser apenas remédios para problemas do judiciário; têm a finalidade de
alcançar a paz; não exigem reforma legislativa; resolvem litígios e até mesmo, 
possivelmente, a lide em seu sentido sociológico, ou seja, em seu viés metajurídico; independem de momento processual específico, seja $1^{\mathrm{a}}, 2^{\mathrm{a}}$ instância ou tribunais superiores, e podem ser extrajudiciais; constituem métodos alternativos de resolução de conflitos; resolvem o mérito da demanda; priorizam a construção dialética da solução do conflito; desoneram o custo do processo; entre outros. (FERREIRA, 2018, p. 25).

A citação acima demonstra claramente a semelhança existente entre os institutos da conciliação e o Termo de Ajustamento de Conduta. Cabe destacar, porém, as características próximas mais relevantes: ambos podem ser rápidos e trazer segurança jurídica; têm a finalidade de alcançar conforme afirma Cintra (2008, p.31); resolvem litígios e até mesmo, possivelmente, a lide em seu sentido sociológico, ou seja, em seu viés metajurídico; independem de momento processual específico e podem ser extrajudiciais.

Importante salientar que a resolução do conflito não necessariamente deve ter o Estado como tutor. Embora a legislação preveja que a conciliação deva ter a presença ou a fiscalização do Estado, seja como juiz, seja como garantidor do cumprimento das regras da arbitragem, "vai ganhando corpo a consciência de que, se o que importa é pacificar, torna-se irrelevante que a pacificação venha por obra do Estado ou por outros meios, desde que eficientes" (CINTRA, 2008, p.31).

Sendo assim, Rodrigues (2011) em relação a construção da solução conciliatória, declara que:

\footnotetext{
A ideia de que a conciliação que resulte num Termo de Ajustamento de Conduta de fato seria um meio menos burocrático e menos dispendioso que o processo, além de ter a vantagem de poder ser construído num ambiente mais propício à autocomposição, extrajudicialmente (RODRIGUES, 2011, p. 161).
}

Theodoro Júnior (2013, p. 33) destaca que a construção da solução seja feita pelas próprias partes, afirmando que o atual Código de Processo Civil "valoriza e estimula a prática da justiça coexistencial, dando ênfase as soluções conciliatórias para facilitar que composição do litígio de maneira a ser construída pelas próprias partes, na medida do possível”.

Neste contexto, busca-se pela efetiva inserção do Termo de Ajustamento de Gestão, modalidade de Termo de Ajustamento de Conduta, como meio de autocomposição, ressaltando, contudo, que as tratativas e o próprio compromisso devem ser norteados pela transparência, ou seja, pelo princípio da publicidade, conforme foi delineado pela Constituição da República Federativa do Brasil no Art. 37, que estabelece:

\section{Revista Cidadania e Acesso a Justiça | e-ISSN: 2526-026X | Belém | v. 5 | n. 2 | p. 78 - 94 |} Jul/Dez. 2019. 
Art. 37. A Administração Pública direta e indireta de qualquer dos Poderes da União, dos Estados, do Distrito Federal e dos Municípios obedecerá aos princípios da legalidade, impessoalidade, moralidade, publicidade e eficiência (...) (BRASIL, C.F, 1988).

Neste sentido, compreende-se que, em se tratando do TAC como meio de promover o desenvolvimento da conciliação evidenciando os princípios apresentados pela Constituição Federal, faz-se destacado o fato de promover as ações de maneira transparente, de maneira a possibilitar os cidadãos à defesa de seus direitos e, ao mesmo tempo a garantia de fazer cumprir os seus deveres perante a legislação vigente, como rege os princípios referentes à legalidade, impessoalidade, moralidade, publicidade e eficiência. (OMMATI, 2017)

Mesmo ocorrendo a explanação referente ao Termo de Ajustamento de Conduta relacionado à classificação e modalidade na qual se encontra inserida, para a compreensão de seu entendimento e relevância no ordenamento jurídico primando pelo cumprimento dos princípios estabelecidos pela Constituição Federal de 1988, outro aspecto deve ser abordado, sendo este referente ao Termo de Ajustamento de Gestão, tendo como foco a necessidade da publicidade, sendo esta um dos princípios do Estado Democrático de Direito.

\section{TERMO DE AJUSTAMENTO DE GESTÃO: A NECESSIDADE DA PUBLICIDADE}

O Termo de Ajustamento de Gestão - TAG foi introduzido, em dois mil e onze, pela Lei Complementar $n^{\circ}$ 102/2008, que dispõe sobre a organização do Tribunal de Contas do Estado de Minas Gerais e tem como principal objetivo regularizar atos e procedimentos dos Poderes, órgãos e entidades. (COSTA, 2012)

A leitura da norma estadual, bem como da Constituição da República Federativa do Brasil, de 1988, demonstram que não há qualquer previsão de sigilo referente ao TAG. Por outro lado, ainda não houve a regulamentação, por parte do Tribunal de Contas do Estado de Minas Gerais, do TAG, conforme prevê o artigo 93-B da referida norma complementar estadual. (COSTA, 2016)

Assim sendo, ainda que carente de regulamentação, não há motivos para que não se dê a devida publicidade aos termos de ajustamento de gestão em tratativas e também celebrados entre os entes públicos. mesmo havendo a previsão de publicação do TAG no diário oficial do Tribunal de Contas do Estado de Minas Gerais - TCE/MG -, tal regra não 
passa de ficção jurídica, uma vez que não é possível ao cidadão ter a informação precisa sobre os termos de ajustamento de gestão em andamento e celebrados que envolvam os entes públicos. (THEODORO JÚNIOR, 2013)

Uma pesquisa pormenorizada no sítio do Tribunal de Contas do Estado de Minas Gerais/MG (2019) não foi capaz de localizar qualquer TAG, mesmo havendo notícias sobre a existência dos mesmos. Ou seja, ainda que haja dispositivos constitucionais e legislativos favoráveis à transparência dos atos dos entes públicos, sobretudo em respeito ao princípio da publicidade insculpido na Constituição da República Federativa do Brasil, de 1988, na prática não há ferramentas disponíveis para que o cidadão exerça seu direito de informação.

A falta de transparência acima mencionada infelizmente faz com que o TAG não seja objeto de controle popular, o que também nos afasta da Constituição. A doutrina de Costa (2016) esclarece sobre o tema:

\begin{abstract}
O Direito Constitucional possibilitou juridicamente a aquisição, pelos homens, da condição de cidadãos mediante a previsão legislativa da inviolabilidade dos direitos fundamentais e das garantias e princípios constitucionais. $\mathrm{O}$ estudo do processo constitucional na pós-modernidade viabiliza indagações acerca da Hermenêutica Constitucional, do controle de constitucionalidade, da aplicabilidade e do exercício dos direitos fundamentais como meio de controle e de fiscalidade da construção dos atos e provimentos estatais. O parâmetro para a interpretação das normas jurídicas é a Constituição, considerada a norma jurídica limitadora dos excessos praticados pelo Estado. O desafio do Direito Constitucional até hoje é compatibilizar o direito fundamental da liberdade com a autoridade estatal, buscando-se a coexistência democrática entre as esferas públicas e privadas. Considerado um dos principais orientadores do Estado Democrático de Direito, a soberania popular viabiliza, através do devido processo constitucional, a participação popular na construção e controle dos atos estatais (COSTA, 2016, p. 77).
\end{abstract}

Ou seja, no momento em que a participação popular é afastada, aniquila-se o Estado Democrático de Direito, fulminam-se os princípios e normas constitucionais e põe-se em dúvida a própria autoridade estatal. Ou seja, defende-se que deve haver transparência e não apenas um ato formal, porque um Termo de Ajustamento de Gestão trata de ato estatal, público. Neste sentido, Ommati (2017) em relação aos princípios e normas constitucionais, o autor declara que:

Por expressa previsão constitucional, todo procedimento é público, a não ser em situações excepcionais em que estão envolvidos direitos relacionados à intimidade de um dos litigantes. Além disso, toda decisão jurisdicional deverá ser fundamentada, sob pena de nulidade. Embora o Texto Constitucional refira-se apenas ao Judiciário, já é cediço em nossa doutrina e jurisprudência que o dever de fundamentação de seus atos não se limita apenas ao Judiciário, estendendo-se também aos atos executivos e legislativos. É dizer: todo e qualquer órgão público

Revista Cidadania e Acesso a Justiça | e-ISSN: 2526-026X | Belém | v. 5 | n. 2 | p. 78 - 94 | Jul/Dez. 2019. 
deve fundamentar suas ações, como forma de permitir que os afetados pela decisão possam controlar seu teor, fiscalizando a atuação dos órgãos estatais (OMMATI, 2017, p. 203).

Dessa maneira, somente através de um procedimento público, efetivamente transparente e fundamentado, haverá legalidade quando das tratativas e também no momento da celebração do Termo de Ajustamento de Gestão, tendo em vista que o interesse público é o principal objeto do compromisso.

A falta do pressuposto da publicidade no Termo de Ajustamento de Gestão faz com que o mesmo não venha a corresponder a Constituição, que consequentemente transformarse-ia em mera "folha de papel". Ou seja, conforme doutrina de Ferdinand Lassale, a Constituição só é legitimada quando representa o efetivo poder social e reflete as forças sociais que constituem o poder (LASSALE, p. 1987). Dessa forma, pelo princípio da publicidade previsto no caput do art. 37 da Constituição, não são permitidas circunstâncias que impeçam os órgãos públicos de respeitar a Constituição e franquear aos cidadãos a ciência e o controle dos termos de ajustamento de gestão.

Costa (2012) em relação à formação participada do mérito processual nas ações coletivas disserta que:

A Democracia é um paradigma de Estado cujo entendimento perpassa pelo exercício amplo das liberdades dos cidadãos orientarem-se por meio da participação nos processos deliberativos dos quais resultam decisões que poderão afetar toda a coletividade. $\mathrm{O}$ constitucionalismo contemporâneo voltou-se para a sistematização da coletivização dos Direitos Fundamentais, que deixam de ser vistos e compreendidos na sua essência apenas sob o prisma individual para, assim, passar a ser pensado no contexto da transindividualidade. A autodeterminação democrática é corolário do exercício da cidadania pelo princípio participativo. Os espaços de interlocução são vistos como locus de formação de opiniões dos cidadãos por meio de redes de discussões que visam construir o consenso coletivo e a gestão dos dissensos, oferecendo subsídios, conteúdos e critérios para deliberações participadamente tomadas e que venham a atender o interesse da coletividade. Além do princípio da participação ser visto com a viga mestra do Estado Democrático de Direito, sabe-se que os fundamentos genuínos de uma democracia encontram-se na legitimidade de controle dos cidadãos dos atos praticados pelo Estado e que versam direta ou indiretamente sobre os direitos da coletividade. (COSTA, 2012, p. 209).

A doutrina de Costa (2012) apresenta claramente a conexão com a ideia da necessidade efetiva de participação dos cidadãos nas discussões que visam construir o consenso coletivo, não havendo que se falar em legitimidade quando não há controle e fiscalização, pelos cidadãos, dos atos praticados pelo Estado. E o Termo de Ajustamento de 
Gestão nada mais é do que um procedimento no qual são tratados de forma direta ou indireta os direitos da coletividade.

\section{CONSIDERAÇÕES FINAIS}

Vistos, portanto, os principais aspectos relacionados ao Termo de Ajustamento de Conduta e à sua variável paralela, o Termo de Ajustamento de Gestão, verificou não haver, na norma estadual, qualquer previsão de sigilo referente ao TAG. Constatou-se que, embora haja previsão de publicação do TAG no Diário Oficial, na prática não há nenhum mecanismo que permita o controle e a fiscalização pelos cidadãos, o que fulmina o princípio democrático.

Dessa forma, pode-se dizer que a publicidade e a participação popular, embora consagrados na Constituição, necessitam efetivação. E neste trabalho não se defende outra proposta que não seja a participação popular e a transparência, a fim de que a Constituição não seja somente a 'vontade de poder'.

Portanto, a fim de que o Termo de Ajustamento de Gestão atinja seu escopo de solucionar demandas que envolvam entes públicos, essencial que seja franqueado ao cidadão o meio adequado para o controle.

Assim, propõe-se que o Tribunal de Contas do Estado disponibilize em seu sítio eletrônico, de forma apropriada, todas as informações referentes aos termos de ajustamento de gestão em tratativas e já finalizados.

\section{REFERÊNCIAS BIBLIOGRÁFICAS}

ALVES, Rogério Pacheco. Improbidade administrativa. 4. ed. Rio de Janeiro: Lumen Juris, 2008 .

ARAÚJO CINTRA, Antônio Carlos de; DINAMARCO, Cândido Rangel; GRINOVER, Ada Pellegrini. Teoria Geral do Processo. 24. ed. São Paulo: Malheiros. 2008.

BRASIL. Lei No 7.347, DE 24 DE JULHO DE 1985. Disponível em: http://www.planalto.gov.br/ccivil_03/leis/17347orig.htm Acesso em 28 de junho de 2019.

BRASIL. Constituição da República Federativa do Brasil. Disponível em: http://www.planalto.gov.br/ccivil_03/constituicao/constituicao.htm Acesso em: 28 de junho de 2019. 
BRASIL. Lei No 8.069, DE 13 DE JULHO DE 1990. Disponível em:

http://www.planalto.gov.br/ccivil_03/leis/18069.htm Acesso em: 28 de junho de 2019.

BRASIL. LEI No 13.105, DE 16 DE MARÇO DE 2015. Disponível em:

http://www.planalto.gov.br/ccivil_03/_ato2015-2018/2015/lei/113105.htm Acesso em: 28 de junho de 2019.

CAPPELlETTI, Mauro; GARTH, Bryant. Acesso à justiça. Tradução de Ellen Gracie Northfleet. Porto Alegre: Sergio Antonio Fabris, 1988.

CAPPELLETTI, Mauro. Os métodos alternativos de solução de conflitos no quadro do movimento universal de acesso à justiça. Revista de Processo, n. 74, ano 19, abril-junho/94, São Paulo: RT.

CARVALHO FILHO, José dos Santos. Ação civil pública: comentários por artigo. 7 ed. Rio de Janeiro: Lumen Juris, 1995.

COSTA, Fabrício Veiga. Liquidez e certeza dos direitos fundamentais no processo constitucional democrático. Coleção Estudos da Escola Mineira de Processo, vol. 13. Rio de Janeiro: Lumen Juris, 2016.

COSTA, Antônio França da. Termo de Ajustamento de Gestão: busca consensual de acerto na gestão pública. Revista TCEMG, 2014. Disponível em:

https://revista1.tce.mg.gov.br/Content/Upload/Materia/2824.pdf Acesso em 15 de agosto de 2019.

COSTA, Fabrício Veiga. Mérito processual: a formação participada nas ações coletivas. Belo Horizonte: Arraes Editores, 2012.

CUNHA, Márcio Felipe Lacombe. Termo de Ajustamento de Conduta e a possibilidade de conciliação na seara da improbidade administrativa. Revista Virtual da Advocacia Geral da União - AGU. DIDIER JÚNIOR, Fredie; ZANETI JÚNIOR, Hermes. Curso de direito processual civil, v. 4, Processo Coletivo. 3. ed. Salvador: JusPodivm, 2008.

FERREIRA, Diogo Ribeiro. Manual do Termo de Ajustamento de Conduta: doutrina, jurisprudência e legislação. Belo Horizonte: Del Rey, 2018.

HESSE, Konrad. A força normativa da constituição. Tradução de Gilmar Ferreira Mendes. Porto Alegre: Sergio Antonio Fabris Editor, 1991.

LASSALE, Ferdinand. O que é uma Constituição Política. Rio de Janeiro: Editora Global, 1987.

MANCUSO, Rodolfo de Camargo. Ação civil pública: em defesa do meio ambiente, do patrimônio cultural e dos consumidores - Lei 7.347/85 e legislação complementar. 11 ed. São Paulo: Revista dos Tribunais, 2009. 
MARTINS JÚNIOR, Wallace Paiva. Probidade administrativa. 4 ed. São Paulo: Saraiva, 2009. pp. 415-416.

MAZZILLI, Hugo Nigro. A defesa dos interesses difusos em juízo: meio ambiente, consumidor, patrimônio cultural, patrimônio público e outros interesses. 21 ed. rev., ampl. e atual. São Paulo: Saraiva, 2008.

MINAS GERAIS. Lei Complementar $n^{\mathbf{o}}$ 102, de 17 DE JANEIRO DE 2008. Disponível em: https://www.almg.gov.br/consulte/legislacao/completa/completa-novamin.html?tipo=LCP\&num=102\&ano=2008 Acesso em: 28 de junho de 2019.

OMMATI, José Emílio Medauar. Uma teoria dos direitos fundamentais. 4. ed. Rio de Janeiro: Lumen Juris, 2017.

PAIXÃO JÚNIOR, Manoel Galdino da. Teoria geral do processo. Belo Horizonte: Del Rey, 2002.

PEREIRA, Marco Antonio Marcondes. Transação no curso da ação civil pública. Revista de Direito do Consumidor: São Paulo: RT, n. 16.2006.

RODRIGUES, Geisa de Assis. Ação civil pública e Termo de Ajustamento de Conduta: teoria e prática. 3 ed. Rio de Janeiro: Forense, 2011.

SANTOS, Daniela Ramos de Oliveira dos. Termo de Ajustamento de Gestão no modelo de controle consensual da administração pública: estudo de caso do Estado de Minas Gerais. Dissertação de Mestrado. Universidade FUMEC, Faculdade de Ciência Humanas, Sociais e da Saúde, Belo Horizonte, MG, 2017.

THEODORO JÚNIOR, Humberto. Curso de Direito processual civil, v. 1, Teoria Geral do direito processual civil e processo de conhecimento. 54 ed. Rio de Janeiro: Forense, 2013.

TRINDADE, André. Para entender Luhmann e o Direito como sistema autopoiético. Porto Alegre: Livraria do Advogado, 2008.

ZANETI JÚNIOR, Hermes. Processo constitucional. RJ: Lumen Juris, 2007. 